\title{
The Effects of Bridge Exercise with Abdominal Drawing-in on Balance in Patients with Stroke
}

\author{
Gui-bin Song ${ }^{1}$, Ju-young $\mathrm{Heo}^{2}$ \\ 'Department of Physical Therapy, Yeungnam University College, Daegu; '2Department of Physical Therapy, Keimyung University Dongsan Medical \\ Cnter, Daegu, Korea
}

Purpose: The aim of this study was to evaluate the effect of Bridge exercise with abdominal drawing-in on static and dynamic balance in patients with stroke.

Methods: Forty patients with stroke participated in this study. Participation was randomly assigned to the Bridge exercise group $(\mathrm{n}=20)$ and the Bridge exercise with abdominal drawing-in group $(n=20)$. A bio-feedback device was used when patients performed the Bridge exercise with abdominal drawing-in. This training was performed without any motion on the patient's spine and upper belly part, and the pressure was held with the biofeedback device as $40-70 \mathrm{mmHg}$. Both groups received training 30 minutes per day, three times per week, for four weeks. Weight bearing, anterior limit of stability, and posterior limit of stability for static balance ability were measured, and Berg balance scale (BBS), Timed up and go test (TUG) for dynamic balance ability were also measured.

Results: Participants showed significant differences between pre- and post-mediation in terms of weight bearing, anterior limit of stability, posterior limit of stability, Berg balance scale, and Timed up and go test $(p<0.05)$. The Bridge exercise with abdominal drawing-in group showed a more significant increase $(p<0.05)$.

Conclusion: According to the results of this study, both exercises were effective for improving the static and dynamic balance ability. However we suggest that the Bridge exercise with abdominal drawing-in is more efficient for increasing balance ability in patients with stroke.

Keywords: Stroke, Bridge exercise, Abdominal drawing-in

\section{서 론}

뇌졸중은 뇌의 산소공급 부족으로 인해 혈액을 공급하는 혈관이 막 혀서 생기는 허혈성 뇌졸중과 혈관이 터져서 생기는 출혈성 뇌졸중 으로 나눌 수 있는 뇌혈관 질환으로 신체의 한쪽이 마비되는 편마비 가 주된 증상이다․ 뇌졸중은 뇌 영역에 따른 문제들을 일으켜, 운동 장애, 감각장애, 지각장애, 언어장애, 인지장애 그리고 배뇨장애와 같 은 문제들을 동반한다. 특히 편마비는 환자의 일상생활을 저해할 수 있는 중요한 요인으로 작용할 수 있다.

뇌졸중으로 인한 편마비는 감소된 균형 능력 저하를 보이며 ${ }^{2}$, 정적 기립자세에서 자세의 흔들림이 증가되어있다. 뇌졸중 환자의 균형능 력은 그들의 기립자세 및 보행을 저해할 수 있는 중요한 요소로서, 뇌 졸중 환자의 자세 흔들림은 같은 연령대의 일반인들에 비해 2 배 이상
이나 높은 것을 알 수 있다. ${ }^{4}$ 뇌졸중 환자들은 비대칭적인 신체 균형 과 보행, 체중이동 및 수의적 움직임의 결함을 보이고, 신체의 중심이 비마비측으로 이동되므로 외부의 흔들림에 대해 대칭적인 체중이동 이 일어나지 않아 균형 유지 능력이 감소되어 있다. ${ }^{5}$ 또한 뇌졸중 환 자들은 무게 중심이 이동할 때마다 고르지 않은 체중 분포로 인하 여, ${ }^{6,78}$ 흔들림의 증가, ${ }^{6}$ 정적 상태에서 버티는 능력의 감소 ${ }^{9}$ 및 비정상 적 근육동원의 결과로 하지의 동요 시 균형조절이 큰 의미를 지니게 된다. ${ }^{10}$ 뇌졸중 환자는 마비 측의 불안정성으로 인해 무게중심을 비 마비 측으로 빨리 이동시키며, 이러한 균형과 보행 능력의 감소는 일 상생활 활동의 장애요소로 작용하여 개인의 독립성을 저해하고 결 과적으로 사회적 활동의 제약 요소가 된다. ${ }^{11}$ 따라서 균형능력의 향 상은 뇌졸중 환자의 중요한 재활 목표이다. ${ }^{12}$

균형과 기능의 향상에 있어서 체간 근육은 중요한 역할을 하는데
Received Jan 12, 2016 Revised Feb 19, 2016

Accepted Feb 22, 2016

Corresponding author Ju-young Heo

E-mail heojuyoung@naver.com
Copylight (C)2016 The Korea Society of Physical Therapy

This is an Open Access article distribute under the terms of the Creative Commons Attribution Non-commercial License (Http:// creativecommons.org/license/by-nc/3.o.) which permits unrestricted non-commercial use, distribution, and reproduction in any medium, provided the original work is properly cited. 
${ }^{13,14} \mathrm{Lehman}$ 등 ${ }^{15}$ 은 저 강도의 체간 근육활동을 필요로 하는 재활운 동에서는 체간 안정화 운동이 중요하다고 설명하면서, 교각운동의 필요성을 강조하였다. 교각 운동은 이미 선행구들에서 다양한 방법 으로 수정되어 적용되어 왔는데 ${ }^{16}$ 기존의 연구들을 살펴보면, Kim과 $\mathrm{Oh}^{17}$ 는 체간 근력 강화운동을 실시한 결과 균형 및 기능 능력이 향상 되었다고 하였고, $\mathrm{Yeom}$ 과 $\mathrm{Lim}^{18}$ 은 슬링을 이용한 체간 안정화 운동 이 뇌성마비 환자들의 체중 지지능력과 정적 균형 능력이 증진되었 다고 보고하였다. $\operatorname{Lim}$ 등 19 은 체간 안정화 운동이 보행능력의 향상에 효과적이며 특히 교각운동은 편마비 환자의 보행 운동성 증가에 유 용한 운동방법이 될 것이라고 하였다. Park 등 20 은 교각 운동 시 체간 으로부터 무릎각도를 크게 하는 것이 임상적으로 더욱 효과적이라 고 보고하였다. 그러나 Richardson과 Jull21은 교각운동 시 심부근육 동시수축(deep muscle co-contraction)이 선행되어야 한다고 하였고, 동시수축을 선행하지 않고 교각운동을 수행 할 경우 과도한 요부 전 만(lumbar lordosis)이 대상작용으로 발생한다고 하였다. 요부 전만을 동반한 교각운동은 순수한 체간 안정화의 효과를 얻기 어려울 수 있 는데, 그 이유는 요부 전만 시 활성화하는 근육과 요부 후만(lumbar kyposis) 시 동원되는 근육이 다르기 때문이다. 그럼에도 불구하고 교 각운동의 대상작용을 고려한 선행 연구는 부족한 실정이다.

복부드로잉-인 기법은 복 벽을 안쪽으로 당김으로써 배가로근과 배속빗근만을 수축시켜 복 내압을 증가시키는 방법이다. 즉, 복부 드 로잉-인 방법은 과도한 요부의 전만이나 골반의 전방 경사를 줄이기 위하여 복 내압을 증가시킴으로써 요부 안정화(lumbar stabilization) 운동을 효과적으로 수행하게 할 수 있다. ${ }^{22}$

따라서 복부드로잉-인 기법을 사용하면 순수한 체간 안정화의 효 과를 기대할 수 있다. 하지만 기존의 연구들은 복부드로잉-인 기법을 이용하여 근활성도를 보는 경우가 많았으며 ${ }^{23,24}$ 정적 균형 및 동적 균 형과 같은 기능적 변화를 논의 하는 연구는 거의 없었다. 그러므로 뇌 졸중 환자와 같은 중추신경계 환자를 대상으로 교각운동을 적용하 여 체간의 근활성도나 근 두께 변화를 알아 본 연구 외에도 복부 드 로잉-인을 결합한 교각운동과 일반적인 교각운동을 비교한 연구도 임상적으로 의미가 있을 것이라 사료된다. 더욱이 선행 연구들은 근 활성도나 근 두께의 변화, 즉 신체 구조의 변화에 대해 연구 목적을 두었으므로, 더 나아가 교각 운동과 복부 드로잉-인을 결합한 교각 운동의 체중 지지 및 균형과 같은 기능적 활동의 변화에 대해 입증하 는 것은 임상적으로 중요한 가치가 있을 것이다.

따라서, 본 연구에서는 뇌졸중 환자에게 교각운동과 복부드로잉인 운동을 결합한 교각운동을 적용했을 때 체중 지지의 변화와 균형 능력의 변화를 알아보고자 하였다.

\section{연구방법}

\section{1. 연구대상}

본 연구는 뇌 단층화 촬영(CT)이나 자기공명영상(MRI)에 의해 뇌졸 중으로 진단을 받고, 대구의 대구 남산병원에서 입원 치료를 하고 있 는 40 명의 뇌졸중 환자들을 대상으로 하며, 하루에 30 분씩 2 번 관절 가동운동, 신장운동, 근력강화운동, 기능적 전기자극치료(functional electrical stimulation, FES)로 이루어지는 기존의 신경계 물리치료에 추가로 교각운동그룹(BG) 20 명과 복부 드로잉-인을 결합한 교각운 동그룹(BDG) 20 명으로 무작위 분류 및 배치하였다. 본 연구에서 정 한 대상자의 선정조건은 다음과 같다.

시야결손과 전정기관에 이상이 없는 자. Modified Aschworth Scale 에서 하지 경직의 정도가 2 단계 이하인 자. 연구자가 지시하는 내용 을 이해하고 수행할 수 있는 인지력을 가진 한국형 간이 정신 상태 판 별검사(Mini-mental state examination-Korea version, MMSE-K) 점수가 24점 이상인 자이다. 모든 참가자들은 Helsinki Declaration 연구윤리 규정에 따른, 연구의 목적과 절차 등의 정보를 제공받고 동의를 한 자 로 구성되었다.

\section{2. 실험방법}

1) 측정도구

(1) 바이오피드백 기구

복부드로잉-인을 결합한 교각운동 대상자는 안정적인 지지면 위 에서 무릎을 90도로 구부리고 누운 자세(Hook-lying position)를 취하 고, 복부드로잉-인 기법을 실시하였다. 환자의 요추 5 번 아래에 압력 바이오피드백 기구(Stabilizer, Chattanooga Group Inc., USA)를 위치시 켜 복부드로잉-인 기법 간 운동에 대한 시각적인 되먹임을 줄수 있도 록 하였으며, 대상자는 연구자의 지시에 따라 하복부를 배꼽 아래쪽 바닥으로 천천히 당기도록 하였다. 동작 간 상복부나 척추의 움직임 이 없도록 하였고, 골반이 중립위치를 유지하는 동안 압력 바이오피 드백 기구가 나타내는 압력의 범위는 $40-70 \mathrm{mmHg}$ 가 유지되도록 하 였다.

\section{(2) 바이오 피드백 분석 시스템}

균형능력을 측정하기 위해서 바이오 피드백 분석 시스템(AP1153 Biorescue, France)을 사용하여, 선 자세에서의 체중 지지, 선 자세에서 안정성 한계(limit of stability)의 전방 이동 범위, 후방이동 범위를 측 정하였다.

(3) 버그 균형척도(Berg bsalance scale, BBS)

이 척도는 14 가지 항목으로 구성되어 있으며 자세유지 능력, 자발적 
운동조절 능력 및 외부 요인에 대한 반사 능력으로 나누어져 있다. 각 항목은 0 점에서 4 점으로 평가할 수 있고 점수가 높을 수록 좋은 균형 기능을 나타낸다. 뇌졸중 한자를 대상으로 한 연구에서 측정자간 신 뢰도는 $r=0.98$, 측정자내 신뢰도는 $r=0.99$ 로 높은 신뢰도를 나타내었 다. 25,26

(4) 일어나 걸어가기 검사(Time up to go test, TUG) 측정자는 팔걸이가 있는 의자를 배치하여 $3 \mathrm{~m}$ 떨어진 곳에 반환점을 표시하고, 대상자는 구두지시에 따라 의자에서 일어나서 반환점까지 걸어가서 돌아온 뒤 의자에 착석하여야 한다. 측정자는 대상자가 해 당 과제를 수행하는 동안 걸리는 시간을 측정한다. 대상자는 기능 수 준에 따라 보조도구를 사용할 수 있다.

측정자 간 신뢰도는 $r=0.98$, 측정자내 신뢰도는 $r=0.99$ 로 높은 신 뢰도를 나타내었다. ${ }^{27}$

\section{2) 중재 방법 및 절차}

교각운동그룹 $(\mathrm{BG})$ 대상자들은 바로 누운 자세에서 교각운동을 실시 하였다. 누운 자세에서 대상자들은 무릎은 $90^{\circ}$ 로 굽힌 상태에서 팔을 체간에서 $30^{\circ}$ 정도 벌린 상태에서 양쪽 손을 바닥에 두고 교각운동을 시작하였다. 이때, 대상자들이 천장을 바라보도록 하여 그들의 머리 와 목을 바른 자세로 두도록 하였다. 복부드로잉-인을 결합한 교각운 동(BDG) 대상자는 안정적인 지지면 위에서 무릎을 $90^{\circ}$ 로 구부리고 누운 자세를 취하고, 복부드로잉-인 기법을 실시하였다. 환자의 요추 5 번 아래에 압력 바이오피드백 기구를 위치시켜 복부드로잉-인 기법 간 운동에 대한 시각적인 되먹임을 줄 수 있도록 하였으며, 대상자는 연구자의 지시에 따라 하복부를 배꼽 아래쪽 바닥으로 천천히 당기 도록 하였다. 실험대상자는 “엉덩이를 올리세요”라는 측정자의 지시 에 따라 골반을 들어올려 “유지하세요”라는 지시에 따라 15 초간 유지 하고 "내리세요"라고 지시하면 골반을 내려 5초 휴식시간을 가진다. 이때 검사자는 연구 대상자에게 숨을 내쉴 때처럼 복부가 약간 들어 가도록 배꼽을 상후방으로 당기도록 지시하였다. 동작 간 상복부나 척추의 움직임이 없도록 하였고, 골반이 중립위치를 유지하는 동안 압력 바이오피드백 기구가 나타내는 압력의 범위는 $40-70 \mathrm{mmHg}$ 가 유지되도록 하였다.

본 실험은 4 주 동안 실시되었으며, 주 3 회 각 30 분씩 실시되었다.

\section{3) 자료분석}

각각 그룹을 측정하여 수집된 자료를 SPSS version 12.0 통계 프로그 램을 이용하여 분석하였다.

대상자들의 일반적 특성을 분석하기 위해서 기술통계를 하였으 며, 각 군의 실험 전과 후의 유의성 검정은 대응표본 비교(paired t-test)
를 하였고, 각 군 간 유의성 검정은 독립표본 비교(independent t-test) 를 실시하였다. 통계학적 유의 수준은 $\alpha=0.05$ 로 설정하였다.

\section{결 과}

\section{1. 일반적 특성}

본 연구에 참여한 전체 대상자는 44 명이었으나, 퇴원 2 명, 개인사유로 실험에 참여하지 못한 2 명으로 최종 실험에는 40 명이 참여하였다.

교각운동 그룹은(BG) 남자 12 명, 여자 8 명으로 총 20 명이었고, 평균 연령은 $51.2 \pm 14.8$ 세, 평균 신장은 $163.5 \pm 8.5 \mathrm{~cm}$, 평균 체중은 $64.1 \pm$ $13.1 \mathrm{~kg}$, 평균 유병기간은 $14.8 \pm 6.1$ 개월이었다. 복부 드로잉-인을 결합 한 교각운동은(BDG)은 남자 환자 6 명, 여자 환자 14 명으로 총 20 명이 었고, 평균 연령은 $48.7 \pm 12.8$ 세, 평균 신장은 $165.9 \pm 8.6 \mathrm{~cm}$, 평균 체중 은 $63.80 \pm 9.26 \mathrm{~kg}$, 평균 유병기간은 $13.4 \pm 8.2$ 개월이었다(Table 1).

\section{2. 두 그룹 간의 체중 지지율 변화}

교각운동 그룹과 복부드로잉-인을 결합한 교각운동은 선 자세에서 마비 측 하지로 체중 지지율이 모두 유의하게 증가되었다 $(\mathrm{p}<0.05)$. 더 욱이 치료 전과 후를 비교하였을 때 복부 드로잉-인을 결합한 교각운 동 그룹에서 교각운동 그룹과 비교하였을 때 유의한 증가를 보였다 $(\mathrm{p}<0.05$; Table.2).

\section{3. 두 그룹 간의 정적 균형 변화}

교각운동 그룹과 복부드로잉-인을 결합한 교각운동은 선 자세에서 안정성 한계(limit of stability)의 전방 이동 범위, 후방 이동 범위가 모 두 유의하게 증가되었다 $(\mathrm{p}<0.05)$. 더욱이 치료 전과 후를 비교하였을 때 복부 드로잉-인을 결합한 교각운동 그룹에서 교각운동 그룹과 비 교하였을 때 유의한 증가를 보였다( $\mathrm{p}<0.05$; Table.2).

Table 1. General characteristic of the subject

\begin{tabular}{llccc}
\hline & & BG $(\mathrm{n}=20)$ & $\mathrm{BDG}(\mathrm{n}=20)$ & $\mathrm{p}$ \\
\hline Gender & $\mathrm{M}$ & 12 & 6 & 0.92 \\
& $\mathrm{~F}$ & 8 & 14 & \\
Age (year) & & $51.2 \pm 14.8$ & $48.7 \pm 12.8$ & 0.90 \\
High (cm) & $163.5 \pm 8.5$ & $165.9 \pm 8.6$ & 0.75 \\
Weight (kg) & $64.1 \pm 13.1$ & $63.80 \pm 9.26$ & 0.95 \\
MMSE-K & & $25.42 \pm 1.38$ & $25.18 \pm 0.82$ & 0.92 \\
Paretic side & RT & 12 & 8 & 0.83 \\
& LT & 8 & 12 & \\
Type of stroke & Infarction & 9 & 11 & 0.64 \\
& Hemorrage & 11 & 9 & \\
Time since stroke (mon) & $14.8 \pm 6.1$ & $13.4 \pm 8.2$ & 0.90 \\
\hline
\end{tabular}

$\mathrm{M} \pm \mathrm{SD}$ : Mean \pm standard deviation, MMSE-K: mini mental state examinationKorea, M: male, F: female, RT: right, LT: left, BG: Bridge training Group, BDG: Bridge exercise with drawing-in maneuver training Group. 


\section{4. 두 그룹 간의 동적 균형 변화}

교각운동 그룹과 복부드로잉-인을 결합한 교각운동은 Timed Up and go Test와 Berg Balance Test에서 유의하게 증가되었다 $(\mathrm{p}<0.05)$. 더 욱이 치료 전과 후를 비교하였을 때 복부 드로잉-인을 결합한 교각운 동 그룹에서 교각운동 그룹과 비교하였을 때 유의한 증가를 보였다 ( $>>0.05$; Table.2).

\section{고 찰}

뇌졸중 환자는 복합적인 기능 장애로 인해 정교한 동작의 수행 및 균 형과 보행능력 저하를 경험하게 되며, 독립적인 일상생활에 필요한 기능적 활동의 제한을 받는다.28,29 뇌졸중으로 인한 편마비 환자는 신 체의 비대칭적인 임상양상으로 인하여, 질량중심과 압력중심점을 비마비측 하지로만 편중시켜서 하지의 비대칭적 형태를 만들어내게 되며, ${ }^{30}$ 편마비 환자는 마비 측 상하지의 근력약화로 기립자세에서 전체 체중의 약 61-80\%를 건측 하지로만 편중하는 양상을 보인다. ${ }^{31}$ 이러한 체중 지지의 비대칭성은 뇌졸중 환자의 균형능력에 막대한 영향을 끼치게 되며 결과적으로 활동성의 제약을 초래한다.

뇌졸중 환자의 체중 지지율을 알아보기 위한 방법으로는 압력중 심(Center of pressure, $\mathrm{COP}$ ) 피라미터의 측정이 있다. 압력중심의 이동 은 선행연구에서 정적인 자세에서 이루어졌으며 그들은 이를 균형능 력과 연계시켜 설명해 왔다. ${ }^{32}$ 또한 압력중심 $(\mathrm{COP})$ 피라미터의 측정 은 지금까지 여러 연구에서 자세조절(postural sway)의 척도로써 사용 되어 오고 있으며, $33,34-36$ 압력 중심의 변인 측정은 지면 반발력(ground reaction force)이 합성된 지점의 변화를 나타내는 것으로 지면과 접촉 하고 있는 모든 압력 점의 무게 평균을 의미한다고 하였다. ${ }^{37}$

본 연구에서는 뇌졸중 환자에게 체간 안정화 운동을 실시하여 정 적인 자세에서 마비 측 체중지지와 자세 기울기를 압력중심 $(\mathrm{COP})$ 을 이용하여 관찰하였다. 일반적인 교각운동을 실시한 그룹과 복부드 로잉-인을 결합하여 교각운동을 실시한 그룹 모두에서 체중지지율 이 $45.5 \pm 8.3$ 과 $47.2 \pm 2.1$ 로 유의하게 증가하였다. $\operatorname{Lim}$ 등 19 은 8 주간 체 간 안정화 운동프로그램을 실시하였는데 마비 측의 후족부의 족저 압이 8 주 후 유의하게 증가하였고, 압력중심의 전후 이동거리는 운동 전에 $8.8 \mathrm{~cm}$, 운동 4 주 후에 $12.3 \mathrm{~cm}$, 운동 8 주후에 $13.2 \mathrm{~cm}$ 로 유의하게 증가하였다고 보고하였다. 이와같은 결과는 마비측의 체중지지율 증 가를 통하여 비대칭적인 편마비 환자의 균형 능력이 교각운동과 복 부드로잉-인 운동을 결합한 교각운동을 통해서 대칭적으로 향상될 수 있음을 입증하고 있다. 특히, Park 등 32 은 압력중심 전후 이동거리 는 보행의 운동성을 나타내는 지표라 하였는데, 본 연구의 압력중심 전후 이동거리를 살펴보면 교각운동 그룹의 안정성 한계의 전방 이 동 범위는 $3,796.9 \pm 3,840.7 \mathrm{~cm}$ 이고 복부드로잉-인을 결합하여 교각운 동을 수행한 그룹은 6,199.9 $\pm 3,982.3 \mathrm{~cm}$ 로 두 그룹 모두 통계적으로 유의한 향상을 보였다. 특히 복부드로잉-인을 결합하여 교각운동을 수행한 그룹은 더욱 더 전방 체중지지에 효과적인 것을 알 수 있었다. 교각 운동 그룹의 안정성 한계의 후방 이동 범위는 는 $1,658.2 \pm 1,173.2$ $\mathrm{cm}$ 이고 복부드로잉-인을 결합한 교각운동 그룹은 $2,732.0 \pm 1,870.0$ $\mathrm{cm}$ 으로 안정성 한계의 전방이동범위와 같이 두 그룹 모두 체중이동 의 향상을 보였으나 복부드로잉-인을 결합한 운동에서 더욱 효과적

Table 2. Comparison of change in balance ability in the training groups with values presented as the mean \pm standard deviation

\begin{tabular}{|c|c|c|c|c|}
\hline & & SBG $(n=20)$ & SBDG $(n=20)$ & $\mathrm{t}$ \\
\hline \multirow[t]{3}{*}{ Affected side WD (\%) } & Pre & $43.0 \pm 6.2$ & $42.6 \pm 2.9$ & 0.409 \\
\hline & Post & $45.5 \pm 8.3$ & $47.2 \pm 2.1$ & 1.937 \\
\hline & $\mathrm{t}$ & $-6.078^{*}$ & $-2.326^{* a}$ & \\
\hline \multirow[t]{3}{*}{ Anterior LOS (mm) } & Pre & $2,281.6 \pm 2,772.5$ & $2,681.8 \pm 3,101.4$ & -0.526 \\
\hline & Post & $5,670.75 \pm 4,291.05$ & $6,199.9 \pm 3,982.3$ & -1.081 \\
\hline & $\mathrm{t}$ & $-5.693^{*}$ & $-2.674^{* a}$ & \\
\hline \multirow[t]{3}{*}{ Posterior LOS (mm) } & Pre & $2,306.4 \pm 1,104.4$ & $1,655 \pm 1,711.4$ & 0.264 \\
\hline & Post & $3,971.70 \pm 2,794.28$ & $2,732.0 \pm 1,870.0$ & 1.320 \\
\hline & $\mathrm{t}$ & $-6.853^{*}$ & $-4.120^{*}$ & \\
\hline \multirow{3}{*}{ TUG (Sec) } & Pre & $22.5 \pm 7.5$ & $21.9 \pm 7.9$ & 0.709 \\
\hline & Post & $18.6 \pm 4.7^{*}$ & $16.74 \pm 3.2$ & 1.002 \\
\hline & $\mathrm{t}$ & $5.031^{*}$ & $3.647^{*_{a}}$ & \\
\hline \multirow[t]{3}{*}{ BBS } & Pre & $42.3 \pm 7.7$ & $38.5 \pm 10.5$ & 1.490 \\
\hline & Post & $45.9 \pm 7.2$ & $45.5 \pm 6.3$ & -0.283 \\
\hline & $\mathrm{t}$ & $-0.886^{*}$ & $-6.974^{* a}$ & \\
\hline
\end{tabular}

BG: Bridge training Group, BDG: Bridge exercise with drawing-in maneuver training Group, WD: weight distribution, LOS: Limit of Stability, TUG: Timed up and go test, BBS: Berg Balance Scale.

* significant difference compared with before therapy at $<0.05$, asignificant difference in gains between the two groups at $<0.05$. 
임을 증명하였다. Park 등른 입각기 동안 압력중심의 이동거리가 클 수록 환자의 균형능력 및 보행 또는 회복 과정이 더 좋은 것으로 평가 할 수 있다고 하였다. 따라서, 본 연구의 결과는 뇌졸중으로 인한 편 마비 환자의 균형능력 향상에 있어서 교각운동과 복부드로잉-인을 결합한 교각운동이 임상적으로 효과 있음을 입증하는 데 시사하는 바가 크다. 정상 성인의 압력중심의 이동은 전후 방향을 중심으로 일 어나며 이와 유사한 방식으로 향상되는 편마비 환자의 균형양상은 환자의 회복 단계와도 상관관계가 있음을 나타내게 된다. 따라서 선 행 연구와도 유사한 결과를 나타낸다고 할 수 있다. ${ }^{32}$

본 연구에서는 일반적인 교각 운동과 복부드로잉-인을 결합한 교 각운동의 효과를 비교하였을 때 두 그룹 다 유의한 결과를 보였으나 복부드로잉-인을 결합한 운동에서 더욱 효과적으로 나타났다. 그 이 유는 교각운동이 체간을 안정화시키고, 둔부와 하지의 근력을 증진 시키려는 운동으로써 임상에서 자주 이용되기는 하나,22 심부근육의 동시수축이 먼저 수행되지 않으면 대상작용으로 인해 과도한 요부 전만이 발생하므로 ${ }^{21}$ 순수한 교각운동의 효과를 얻기 어렵기 때문이 다. Stevens 등 23 은 건강한 대상자에서 교각운동을 할 때 요추를 중립 자세(lumbar neutral spine position)로 유지하면 요추를 중립자세로 유 지하지 않고 교각 운동을 할 때보다 배속빗근과 배곧은근의 근 활성 도가 증가하였다고 보고하였으며, 배바깥빗근의 근 활성도는 유의한 차이가 없었다고 보고하였다. 그리고 흥부의 허리엉덩갈래근(iliocostalis lumborum pars thoracis)의 근 활성도가 유의하게 감소하였다고 보고하였다. 따라서 복부드로잉-인을 결합한 교각운동은 과도한 신 전과 요부 전만을 막아주어 보다 효과적인 체간 안정성을 획득할 수 있다. 본 연구에서는 보다 정확한 복부 드로잉-인을 결합한 교각 운동 의 효과를 알아보기 위하여 압력 생체 피드백 장치(pressure biofeedback unit)를 사용하였는데 Jull등 38 은 압력 생체 피드백 장치는 압력 계가 연결되어 있으며 내부 압력의 증가로 팽창되는 비탄력적 장치 로 요부 안정화 운동을 평가하기에 임상적으로 유용하다고 하였다. 따라서 본 연구에서 압력 생체 피드백 장치를 이용한 복부드로잉-인 을 결합한 교각 운동은 대상작용을 최소화 하여 교각운동의 순수한 결과를 얻을 수 있었으며 더불어 동적 및 정적 균형에도 효과적임을 입증할수 있었다.

뇌졸중 환자에게 체간 안정화 운동을 실시한 결과 일상활동 체력 과 자세조절능력의 향상을 가져 오고, ${ }^{39}$ 보행능력이 증진된다는 보고 가 증가하고 있는 추세이다. ${ }^{40}$ 따라서 본 연구에서는 대표적인 동적 균형 평가 도구인 burg balance scale (BBS), time up and go (TUG) 측정 을 통해 기능적 효과도 알아보았다. BBS의 평가 결과 일반적인 교각 운동 그룹은 $18.6 \pm 4.7$, 복부드로잉-인을 결합한 교각운동 그룹은 $16.74 \pm 3.2$ 로 두 그룹 모두 통계적으로 유의하였고, TUG 또한 $45.9 \pm$ $7.2,45.5 \pm 6.3$ 으로 통계적으로 유의하였다. 이러한 결과는 근육의 구
조적 변화뿐만 아니라 동적 균형과 같은 기능적 활동에도 교각 운동 이 효과적임을 입증하고 있다.

본 연구는 교각운동과 복부드로잉-인을 결합한 교각운동이 체중 지지 및 동적 균형에 미치는 영향을 알아보기 위해 실시되었다. 본 연 구의 결과로 두 운동 모두 뇌졸중 환자들의 마비측 하지에 체중지지 능력을 증진시키며, 동적 균형 능력을 증진시키는 것을 알 수 있었다. 본 연구에 따르면, 복부드로잉-인을 결합한 교각운동은 일반적인 교 각운동을 실시하였을 때보다 더 나은 통계적 유의확률을 나타내었 다. 이는 복부드로잉-인과 결합한 교각운동이 체간 근육의 활성화와 근력을 증진시켜주어, 체간의 안정화가 이루어져 체중 지지능력과 균 형능력에 긍정적 영향을 준 것이라 사료된다. 선행 연구에서도 체간 안정화를 위해 교각 운동시 체간 근육들의 근 활성도가 증가되어 효 과적이라고 제시하였는데, ${ }^{41-44}$ Bierkefors 등 ${ }^{41}$ 은 9명의 여성을 대상으 로 하여 체간 안정화 운동으로 교각 운동을 실시하여 배가로근 (Transversus Abdominis, TrA)만 배곧은근(Rectus Abdominis, RA)으 로부터 독립적으로 활성화 되는 것을 발견하였고, 최대 $4-43 \%$ 까지 효 과가 있음을 나타내었다. 또한 Kho등 44 은 복부 드로잉-인을 결합한 교각운동 시 큰볼기근(Gluteus Maximus)와 척추세움근(Erector Spinae)의 활성도를 관찰한 결과 복부 드로잉-인을 결합한 교각운동이 척추세움근의 근활성도를 줄이면서 큰볼기근을 강화시키는 데 유 용하다고 제안하였다. Seo등 45 은 경직성 편마비 아동의 둔부에 테이 핑을 하여 선 자세와 동적 균형 능력을 평가하였는데, 선 자세에서 골 반의 전방 경사각의 평균값을 비교한 결과 $17.69^{\circ}$ 에서 $13.92^{\circ}$ 로 통계학 적으로 유의하게 감소하였다. 이것은 둔부 테이핑이 큰볼기근의 수 축을 도와주어 둔부 신전이 증가되었음을 나타내며, 큰 볼기근이 신 전근으로 작용하여 골반을 중립 위치에 유지하도록 하여 정적 및 동 적 균형에 영향을 미치는 것을 알 수 있다. 환측 둔부의 테이핑이 둔 부 신전근을 활성화시키고 한발 서기 및 동적 균형의 개선을 시키는 것은 본 연구와 같은 맥락이라고 볼 수 있다.45,46이전 연구들을 살펴 보면, 교각운동과 복부드로잉-인을 결합한 교각운동이 체간 근육의 근 활성도와 근력을 증진시켜 체간 안정화에 기여한다는 것을 알 수 있으며, 이러한 연구는 많이 이루어지고 있으나, 체간 안정화가 동적 균형 능력 증진에 직접적인 영향을 준다는 점을 연구한 논문은 부족 하다. 따라서 본 연구는 체간의 안정화를 증가시키는 두 종류의 운동 방법이 뇌졸중 환자들의 체중 지지능력과 균형능력을 증진시킨다는 것을 확인하였다.

본 연구는 40 명의 대상자로 얻어진 결과를 모든 뇌졸중 환자들에 게 일반화하기 어렵다는 점과, 병원에서 생활하고 있는 뇌졸중 환자 들의 병원 생활 24 시간을 통제하기가 어려웠다는 제한점이 있다. 그 러나 복부드로잉-인을 결합한 교각운동이 체간 근활성도와 같은 구 조적변화뿐만 아니라 체중지지 및 체중이동과 동적 균형에도 효과 
가 있음을 입증하였다. 향후 연구에서는 증가된 체중지지 내에서 체 중지지 분포도나 보행과 같은 기능적 활동 시 미치는 영향에 대해서 도 활발한 연구가 이루어져야 할 것이다.

\section{REFERENCES}

1. Choi AY, Cho WS. The effects of mechanical horseback riding exercise on the dynamic balance in patients with cerebral infarction. J Korean Soc Phys Ther. 2014;26(2):123-9.

2. Song GB, Hwangbo G. The effect of a rehabilitational sliding machine and conventional neurological physical therapy on the balance of patients with hemiplegia. J Phys Ther Sci. 2015;27:171-3.

3. Song BK. Effect of somatosensory stimulation on upper limb in sensory, hand function, postural control and ADLs within sensorimotor deficits after stroke. J Korean Soc Phys Ther. 2012;24(5):291-9.

4. Nichols DS. Balance retraining after stroke using force platform biofeedback. Phys Ther. 1997;77(5):553-8.

5. Dickstein R, Nisan M, Pilar T et al. Foot-ground pressure pattern of standing hemiplegic patients: Major characteristics and patterns of improvement. Phys Ther. 1984;64(1):19-23.

6. Turnbull GL, Charteris J, Wall JC. A comparison of balance control in standing between normal and ambulant hemiplegic subjects. Phys Ther. 1994;74:33.

7. Shumway-Cook A, Anson D, Haller S. Postural sway biofeedback: Its effect on reestablishing stance stability in hemiplegic patients. Arch Phys Med Rehabil. 1988;69:395-400.

8. Bohannon RW, Larkin PA. Cybex II isokinetic dynamometer for the documentation of spasticity. Phys Ther. 1985;65:46-7.

9. Lee WA, Deming L, Sahgal V. Quantitative and clinical measures of static standing balance in hemiparetic and normal subjects. Phys Ther. 1988; 68:970-6.

10. Badke MB, Duncan PW. Patterns of rapid motor responses during postural adjustments when standing in healthy subjects and hemiplegic patients. Phys Ther 1983;63:13-20.

11. Lee MS, Lee KN. Effects of single-leg stance training of the involved leg on standing balane and mobility in patients with subacute hemiplegia. J Korean Soc Phys Ther. 2012;24(2):157-62.

12. Shim HM, Cho HY, Choi WH. Effects of the Trunk Stabilization Exercise on muscle activity in lumbar region and balance in the patients with hemiplegia. J Korean Soc Phys Ther. 2014;2(1):33-40.

13. Spinazzola L, Cubelli R, Della Sala S. Impairments of trunk movements following left or right hemisphere lesions: Dissociation between apraxic errors and postural instability. Brain. 2003;126(12):2656-66.

14. Karatas M, Cetin N, Bayramoglu M et al. Trunk muscle strength in relation to balance and functional disability in unihemispheric stroke patients. AmJ of Phys Med Rehabil. 2004;83(2):81-7.

15. Lehman GJ, Hoda W, Oliver S. Trunk muscle activity during bridging exercises on and off a swiss ball. Chiropr Osteopat. 2005;13-4.

16. Kim ChY. The effects of a trunk stability exercise on trunk strengthening, dynamic balance and walking in the persons with chronic stroke. Sahmyook University. Dissertation of Master's Degree. 2008.

17. Oh JL, Kim JS. The effect of trunk muscle strength training on sitting balance of children with spastic cerebral palsy. J Kor Phys Ther. 2004; 16(1):87-102

18. Yeom JN, Lim GG. Change of static and dynamic foot pressure after trunk stabilization exercise in children with spastic diplegic cerebral palsy. J Kor Phys Ther. 2014;26(4);274-9

19. Lim JS, Song JM, Kim JS. The effect of core Stabilization Exercise on Foot Pressure in Hemiplegic Patients. J Korean Soc Phys Med. 2011; 6(2):109-18.

20. Park MCh, Heo JK, Lee JS. The effects of bridge exercise with different knee joint angles on stroke patients' trunk muscle activity at different knee joint angles. J Korean Acad. 2011;3(1):61-72.

21. Richardson CA, Jull GA. Muscle control-pain control: What exercises would you prescribe?. Man Ther. 1995;1:2-10.

22. Kisner C, Colby LA. Therapeutic Exercise: Foundations and Techniques. 4th ed. Philadelphia, PA, F.A. Davis. 2002.

23. Stevens VK, Coorevits PL, Bouche KG et al. The influence of specific training on trunk muscle recruitment pattern in healthy subjects during stabilization exercises. Man Ther. 2007;12:271-9.

24. Oh JS, Cynn HS, Won JH et al. Effects of performing an abdominal drawing-in maneuver during prone hip extension exercise on hip and back extensor muscle activity and amount of anterior pelvic tilt. J Orthop Sports Phys Ther. 2007;37(6):320-4.

25. Beninato M, Portney LG, Sulivan PE. Using the international classification of functioning, disability and health as a framework to examine the association between falls and clinical assessment tools in people with stroke. Phys Ther. 2009;89(8):816-25.

26. Kim JH. A study on the correlation between static, dynamic standing balance symmetry and walking function in stroke. J Korean Soc Phys Ther. 2012;24(2):73-81.

27. Podsiadlo D, Richardson S. The timed up \& go: a test of basic functional mobility for frail elderly persons. J Am Geriatr Soc. 1991;39(2)142-8.

28. Jorgensen L, Engstad T, Jacobsen BK. Higher incidence of falls in longterm stroke survivors than in population controls: depressive symptoms predict falls after stroke. Stroke. 2002;33(2):542-7.

29. Geurts ACH, DeHaart M, VanNes IJW et al. A review of standing balance recovery from stroke. Gait Posture. 2005;22:267-81.

30. Laufer Y, Dickstein R, Resnik S et al. Weight-bearing shifts of hemiparetic and healthy adults upon stepping on stair of various heights. Clin Rehabil. 2000;14(2):125-9.

31. Sckley CM, Lincoln NB. Single blind randomized controled trial of visual feedback after stroke: Effects on stance symmetry and function. Disabil Rehabil. 1997;19(12):536-46.

32. Park JW, Nam KS, Baek MY. The relationship between the planar center of pressure displacement and dynamic balance measures in hemiplegic gait. Phys Ther Korea. 2005;12(1):11-21.

33. de Haart M, Geurts AC, Huidekoper SC et al. Rocovery of standing balance in postacute stroke patients: A rehabilitation cohort study. Arch Phys Med Rehail. 2004;85(6):886-95.

34. Garland SJ, Wilemes DA, Ivanova TD et al. Recovery of standing balance and functional mobility after stroke. Arch Phys Med Rehabil. 2003;84(12):1753-9.

35. Geurts AC, Mulder TW, Nienhuis B et al. Postural reorganization following lower limb amputation. Possible motor and sensory determinants of recovery. Scand J Rehabil Med. 1992;24(2):83-90. 
36. Pyoria O, Era P, Talvitie U. Relationship between standing balance and symmetry measurements in patients following recent strokes (3 weeks or less)or older strokes(6 months or more). Phys Ther. 2004;84(2):128-36.

37. Latash ML, Fereira SS, Wieczorek SA et al. Movement sway: Changes in postural sway during voluntary shifts of the center of pressure. Exp Brain Res. 2003;150(3):314-24.

38. Jull GA, Richardson CA, Toppenberg R et al. Towards a measurement of active muscle control for lumbar stabilization. Aust J Physiother. 1993; 39:187-93.

39. Na SW. Effect of hip adductor co-contraction on trunk muscle activation during bridge exercise in healthy young individuals. J Korean soc phys med. 2012;7(3):275-82.

40. Choi HJ, Jeong JW. The effect of 6 weeks intensive core stability training on functional fitness and postural control ability of stroke patients. Korean Society of Exercise Physiology. 2008;17(4):505-14.

41. Bjerkefors A, Ekblom MM, Josefsson K et al. Deep and abdominal mus- cle activation during trunk stabilization exercises with and without instruction to hollow. Man Ther. 2010;15(5):5027.

42. Guthrie RJ, GrindstaffTL, Croy T et al. The effect of traditional bridging or suspension-exercise bridging on lateral abdominal thickness in individuals with low back pain. J Sport Rehabil. 2012;21(2):151-60.

43. Konrad P, Schmitz K, Denner A. Neuromuscular evaluation of trunktraining exercises. J Athl Train. 2001;36(2):109-18.

44. Kho EK, Jang JH, Jung DY. Effect of abdominal hollowing on muscle activity of gluteus maximus and erector spinae during bridging exercise. J Korean Soc Phys Ther. 2012;24(5):319-24

45. Seo HJ, Kim JH, Son KK et al. The effect of gluteal taping on posture and balance during standing in children with hemiplegic cerebral Palsy. J Korean Soc Phys Med. 2014;9(4):391-8

46. Karien MW, Bafana HS, Johannes JS et al. Effect of kinesio taping on explosive muscle power of gluteus maximus of male athletes. South African Journal of Sports Medicine. 2012;24(3):75-80. 